\title{
DESPEDIDA E DESPRENDIMENTO NO PEQUENO CADERNO DO ORIENTE DE EUGÉNIO DE ANDRADE
}

Antonio José Bezerra de Menezes $\mathrm{Jr}^{1}$

RESUMO: O presente trabalho analisa algumas referências poéticas chinesas e japonesas presentes no Pequeno Caderno do Oriente do poeta Eugénio de Andrade, escrito em Macau no ano de 1990, assim como o tom de despedida decorrente do processo de devolução do antigo território português ao governo da República Popular da China.

PALAVRAS-CHAVE: poesia portuguesa contemporânea, Macau.

ABSTRACT: This work analyzes some Chinese and Japanese poetical references present in the Notebook of the Orient (Pequeno Caderno do Oriente) by the poet Eugénio de Andrade, written in Macau in 1990, as well as the farewell feeling caused by the process of devolution of the ancient Portuguese territory to the People Republic of China.

KEYWORDS: contemporary Portuguese poetry, Macau.

\footnotetext{
${ }^{1}$ Professor do Curso de Língua e Literatura Chinesa da USP e Mestrando em Literatura Portuguesa pelo DLCV-FFLCH-USP.
} 


$$
\begin{array}{cr}
\text { “concluída a obra } \quad \text { ele não se atém } \\
\text { e só por não se ater } \quad \text { ela não se esvai" }
\end{array}
$$

Dao De Jing, capítulo 2

O "Pequeno Caderno do Oriente", composto de 12 pequenos poemas, apontamentos e textos em prosa poética, foi escrito pelo poeta português Eugénio de Andrade (1923-2005) por ocasião de uma visita à Macau feita em outubro de 1990. A obra foi ilustrada pelo arquiteto e artista plástico Carlos Marreiro e publicada na Revista de Cultura de Macau em novembro de 1993. Posteriormente, a obra foi vertida para o inglês e para o chinês por Rui Cascais e Yao Jingming, sendo editada em 2002 por iniciativa do Instituto Camões e do Instituto Cultural de Macau.

Nessa obra, o antigo território português devolvido à China em 20/12/1999, transforma-se no espaço da memória e das referências poéticas do autor, dialogando sobremodo com as figuras de Camilo Pessanha (1867-1926) e Li Bai (__, 701-762)2 num discurso marcado pelo tema da despedida e por um certo exercício de desprendimento. Esse processo de ver a cidade por um prisma histórico sincrônico em que todos os tempos estão presentes é percebido por Mônica Simas em outros poetas macaenses:

Nas etapas de ver a cidade, os poetas e suas biografias são
acoplados aos referenciais urbanos, delineando-se a memória da
literatura na própria memória da cidade. ${ }^{3}$

No caso de Camilo Pessanha, o Pequeno Caderno começa e termina justamente com dois textos dedicados à ele. No primeiro texto, intitulado "Camilo Pessanha, o Mestre", o autor recorda a maneira casual com que conheceu a obra do poeta e sintetiza os motivos de sua admiração, o que abrange o próprio modo de viver "desprendido" de Camilo Pessanha “(...) à margem da impenitente e sentenciosa e sobranceira verborréia

\footnotetext{
${ }^{2}$ Famoso poeta da Dinastia Tang (_, 618-907) considerada a época de ouro da poesia clássica chinesa.

${ }^{3}$ SIMAS, Monica - Margens do Destino, p. 244.
} 
nacional (...)"4. No segundo texto, intitulado "O Nome na Água", registra sua visita ao cemitério onde está enterrado o autor de Clepsidra e na qual homenageia, numa espécie de desagravo, sua vida e sua obra escritas fora dos padrões e convenções da época.

No caso de Li Bai, Eugénio de Andrade identifica-o como sua principal referência poética e cultural do mundo chinês. Assim escreve, no texto "As Montanhas Verdes" a propósito de um poema de Li Bai:

$\mathrm{E}$ as montanhas verdes ao norte da muralha, que não eram de Macau, mas da China, ou com mais rigor: da China de Li Bai, em versos que Ezra Pound havia traduzido, e eram de um dos poemas da minha vida. Na última linha, no momento em que os dois amigos se separam, ouvem-se apenas os relinchos dos seus cavalos. Talvez chorassem, como os de Aquiles na morte de Pátroclo. ${ }^{5}$

O poema mencionado de Li Bai é o seguinte, acompanhado da tradução feita pelo poeta Haroldo de Campos (1929-2003):

Montanha verdeazul além da torre norte

Água clara em redor da cidade este

Aqui afinal nos separamos:

Milhas e milhas através da relva seca

Nuvens voláteis: o ânimo de quem viaja

$\mathrm{O}$ adeus sol-posto a um velho amigo

\footnotetext{
${ }^{4}$ PCO, "Camilo Pessanha, o Mestre" p. 11. Ainda nesse primeiro texto, Eugénio de Andrade solta duas farpas: uma contra a proliferação de vanguardas "inócuas em matéria de subversão" e outra contra a crítica universitária que exibiria "um amor pela poesia que nunca teve". Poderia-se perguntar por que o papel da arte deve ser apenas o da subversão (segundo motivações ideológicas mais ou menos dogmáticas) e o que significa dizer que a universidade não ama a poesia (uma acusação no mínimo injusta). $\mathrm{O}$ autor, no entanto, não desenvolve esses temas que ficam apenas no campo das provocações.

${ }^{5}$ PCO, “As Montanhas Verdes" pp. 19-20.
} 
Mãos ondulando na partida

Ao ríspido nitrido dos cavalos. ${ }^{6}$

O poeta e orientalista norte-americano Witter Bynner (1881-1968) oferece uma tradução um pouco diferente, e um pouco mais clara, especialmente com relação ao penúltimo verso em que se estabelece um "pacto da memória" entre os amigos que se separam:

With a blue line of mountains north of the wall,

And east of the city a white curve of water,

Here you must leave me and drift away

Like a loosened water-plant hundreds of miles....

I shall think of you in a floating cloud;

So in the sunset think of me.

...We wave our hands to say good-bye,

And my horse is neighing again and again. ${ }^{7}$

Eugénio de Andrade conclui o texto retomando o tema da separação e estabelecendo uma analogia com o fazer poético “(...) como se a poesia não fosse senão uma inevitável e longa despedida" ${ }^{\prime \prime}$. Essa analogia se converte em metáfora da vida e sua finitude que transparece nos poemas "Jardim de Lou Lim leoc" e "Balança" que traz ainda a idéia de um juízo particular no qual a poesia atuaria como amor de salvação:

Deste jardim o que levo comigo é um ramo de bambú para servir de espelho ao resto dos meus dias.

No prato da balança um verso basta para pesar no outro a minha vida. ${ }^{10}$

O bambu também é novamente evocado no poema "Templo da Barra" como objeto transcendente que apesar da sua simplicidade se relaciona com o céu:

\footnotetext{
${ }^{6}$ CAMPOS, Haroldo de - "Minha Relação com a Poesia Chinesa" in Revista de Cultura, Instituto Cultural de Macau, Outubro/Dezembro de 2005, n 25 (II Série), p. 240.

${ }^{7}$ BYNNER, Witter - The Jade Mountain: A Chinese Anthology, New York : Alfred A. Knopf, 1929. Reproduzidos no site da Universidade da Virginia: URL: http://etext.virginia.edu/chinese/frame.htm, poema 102.

${ }^{8}$ PCO, “As Montanhas Verdes” p. 20.

${ }^{9}$ PCO, "Jardim de Lou Lim leoc", p. 15.

${ }^{10}$ PCO, "Balança", p. 24.
} 
O verde dos bambus mais altos é azul

ou então é o céu que pousa nos seus ramos ${ }^{11}$

Nestas três intervenções poéticas, Eugénio de Andrade escolhe uma forma sintética que lembraria o haikai japonês, marcado pela simplicidade da estética Zen, assim definido por Haroldo de Campos:

No pensamento por imagens do poeta japonês o haicai funciona como uma espécie de objetiva portátil, apta a captar a realidade circunstante e o mundo interior, e a convertê-los em matéria visível. ${ }^{12}$

Finalmente no texto "Ofício de Paciência", no qual se elogia o labor da gente simples e entre cujas artes também se inclui a poesia ${ }^{13}$, Eugénio de Andrade conclui com uma imagem que parece conciliar o sentimento de ocaso da vida com o de desprendimento em relação à obra, como se esta fosse apenas uma "estrela de papel", que assim como os bambus do "Templo da Barra", também sobe em direção ao céu:

(...) a rapariga leva à boca uma flauta - um fio de música sobe, sobe no ar como estrela de papel. Não tardará que anoiteça. ${ }^{14}$

Despedida e desprendimento que também se aplicam à própria Macau cuja devolução ao governo chinês, acordada em 1987, entrava no horizonte de expectativas da comunidade lusófona e sua literatura na derradeira década de 1990:

Macau vivia o momento de transição e, naquele momento, valores e signos transitavam na construção literária, trazendo novas reflexões acerca das possibilidades de interculturalidade na linguagem. Atentos à antecipação do futuro, escritores incorporaram em suas criações literárias níveis diferenciados de efeitos acionais, que vão da cognição à proliferação imagética de despedidas, expectativas, recordações e transformações e, dessa forma, criaram novas condições literárias. ${ }^{15}$

\footnotetext{
${ }^{11}$ PCO, "Templo da Barra", p.21. Surge aqui talvez uma reminiscência da famosa passagem evangélica sobre o grão de mostarda (Mt 13,31) e sobre os lírios do campo (Mt 6,28-29).

${ }^{12}$ CAMPOS, Haroldo de - "Visualidade e Concisão na Poesia Japonesa" in A Arte no Horizonte do Provável, p. 65.

${ }^{13}$ A esse propósito também escreveu o poeta Paul Valery (1871-1945): "Meu trabalho é um trabalho de paciência executado por um impaciente" in CAMPOS, Augusto de - Paul Valéry: A Serpente e o Pensar. São Paulo: Brasiliense, 1984, p. 76.

${ }^{14}$ PCO, "Ofício de Paciência", p. 14.

${ }^{15}$ SIMAS, Monica - Margens do Destino, p. 245.
} 


\section{BIBLIOGRAFIA:}

ANDRADE, Eugénio de - "Pequeno Caderno do Oriente" in Revista de Cultura, Instituto Cultural de Macau, Novembro de 1993.

BYNNER, Witter - The Jade Mountain: A Chinese Anthology

New York : Alfred A. Knopf, 1929.

CAMPOS, Augusto de - Paul Valéry: A Serpente e o Pensar.

São Paulo: Brasiliense, 1984,

CAMPOS, Haroldo de - "Minha Relação com a Poesia Chinesa" in Revista de Cultura, Instituto Cultural de Macau, Outubro/Dezembro de 2005, nº 25 (II Série), pp. 231-240. . "Visualidade e Concisão na Poesia Japonesa" in A Arte no Horizonte do Provável. São Paulo: Perspectiva, 1977, pp. 63-75.

Entrevista com Carlos Marreiros - Jornal Tai Chung Pou (Macau) edição eletrônica disponível no site: http://taichungpou.blogspot.com/2007/10/carlos-marreiros-ementrevista.html acessado em 01/01/2009.

Entrevista com Yao Jinming - Jornal Tai Chung Pou (Macau) edição eletrônica disponível no site: http://taichungpou.blogspot.com/2007/11/poesia-por-yao-o-bairrodentro-do.html acessado em 01/01/2009.

LAOZI - Dao De Jing. Tradução e comentários de Mario Bruno Sproviero.

São Paulo: Hedra, 2002, $1^{a}$ edição.

SIMAS, Monica - Margens do Destino: Macau e a Literatura em Língua Portuguesa.

São Caetano do Sul, SP: Yendis Editora, 2007.

University of Virginia Library - Chinese Text Initiative - 300 Tang Poems http://etext.virginia.edu/chinese/frame.htm acessado em 02/01/2009. 